\title{
Compensation and Continuity
}

Wrongdoers may incur duties to compensate the victims of their wrongs. A prominent explanation of this fact, endorsed in different forms by John Gardner, Joseph Raz, Arthur Ripstein, and Ernest Weinrib, is that an aspect of the pre-wrong normative situation continues in some way and now requires the wrongdoer to compensate. In this article, I identify and assess three versions of this view - duty continuity, right continuity, and reasons continuity. I argue that each version is defensible, once properly articulated. Even if the paper's defence of the continuity explanations is rejected, it hopefully achieves the more modest goal of clarifying and deepening these accounts by stating them more precisely than before, and by considering objections their proponents have not addressed.

The paper is in six sections. The first introduces and contrasts this type of explanation of compensatory duties with others, and demonstrates the importance of a defence of continuity theses. The second section defends a version of 'duty continuity': the idea that the duty breached continues to bind the duty-bearer in such a way as to require compensation postbreach. The third section examines 'reasons continuity': the idea that the reasons which grounded the duty breached continue to demand conformity post-breach and that compensation is often the next-best way of conforming to those reasons. It argues that reasons continuity is true, but has no significant theoretical advantage over duty continuity. The fourth section examines 'right continuity': the idea that the right infringed justifies both the duty not to interfere with the right and the duty to compensate. It argues that right continuity enjoys no advantage over reasons or duty continuity. The fifth section considers the scope of compensatory duties justified by continuity explanations. The sixth section considers objections.

Three clarifications are in order. First, what is a 'compensatory' duty? As I will understand it, a duty to compensate is a duty to place a person in the position, with respect to their interests, which they would have been in had some event not occurred, or to put the person in a position which is close to that position. Second, the article is primarily concerned with compensatory duties that arise from all-things-considered wrongs or pro tanto wrongs. It understands a wrong as the breach of a moral duty. ${ }^{1}$ It is not assumed that all wrongs give rise to duties of compensation nor that duties of compensation only arise from wrongs. But the focus is upon those

\footnotetext{
* [Acknowledgments]

${ }^{1}$ Some may deny that the conduct in cases of pro tanto wrongdoing is wrongful in any sense. See, for example, RJ Wallace, The Moral Nexus (Princeton, 2019), 171-172. Readers who have this view can replace references to 'pro tanto duties not to X' with 'strong reasons not to X'.
} 
duties that arise after the commission of a wrong. ${ }^{2}$ A parent might have a duty to compensate their child who is injured as a result of an earthquake, but this need not arise from any wrong on the parent's part. Third, the paper, while it draws on legal examples, is primarily concerned with moral duties to compensate that exist independently of the law. The analysis will clearly have implications, however, for the moral justifiability of legal duties to compensate.

(1) Continuity theses: introduction

Consider the following example:

Arm. A intentionally removes B's arm without justification. A prosthetic arm, which will have the same functionality as B's removed arm had, costs $£ 500$.

Intuitively, if B demands that A do so, A has a duty to provide B with the prosthetic arm, or provide A with the means of acquiring it (i.e. $£ 500$ ). ${ }^{3}$

The explanations for this phenomenon that I examine here hold that the way things stood, normatively, between the victim and injurer, prewrongful-harm, explains the normative position between them postwrongful-harm in relation to compensation. ${ }^{4}$ As these explanations rely upon the idea that the pre-breach normative position 'continues' in some way post-breach, I refer to them as 'continuity theses', following John Gardner. 5 The notion of 'continuity' can be understood in at least three ways. First, it can be understood as continuity of justification: what justifies the normative requirement breached also justifies the duty to compensate. ${ }^{6}$ Call this 'justificatory continuity'. Second, it could be understood as persistence through time - pre-breach or non-conformity and post-breach or non-conformity - of a single normative entity. Call this 'constitutive continuity'. Third, it could be understood as the moral intelligibility of a normative requirement, given some other normative requirement. For instance, a duty to apologise is intelligible given the importance of a moral requirement breached, but it is not the persistence through time of the duty breached, and it is not clear that it is justified by

\footnotetext{
2 This leaves open whether the duty to compensate arises in virtue of the wrong. The paper's starting point is the intuitive idea that wrongdoing sometimes gives rise to duties to compensate. It leaves open at the outset whether the compensatory duty is grounded in the wrong or whether wrongdoing is merely one important causal occasion for the triggering of compensatory duties: see further below, X.

3 The relevance of B's demand is considered below, $\mathrm{X}$.

${ }^{4}$ Other normative features of the post-breach situation, such as a duty to apologise, may have independent explanations.

5 J Gardner, Torts and Other Wrongs (OUP, 2019), ch 2.

${ }^{6}$ I use the term 'requirement' to cover 'duty' and 'reason'.
} 
Legal Theory - Revised Submission

the same facts as the duty breached. I will focus on continuity in the first two senses.

There are essentially three continuity theses in the literature.

Duty continuity: the duty-bearer's duty continues post-breach, and post-breach requires the duty-bearer to compensate.

Right continuity: the right of the person that has been violated or infringed continues after violation or infringement and requires the violator or infringer to compensate. ${ }^{7}$

Reasons continuity: the reason or reasons grounding a duty continue post-breach, and next-best conformity to those reasons may require compensation. ${ }^{8}$

Applied to Arm, Duty continuity, for example, holds that there is a continuing duty on the part of $\mathrm{A}$ which requires $\mathrm{A}$ to compensate $\mathrm{B}$. One possible such duty is A's duty not to harm B. To the extent that B's condition is truly reparable, A's paying compensation to B may make it the case that B will not be harmed, or harmed to the same extent, by B's conduct.

Two points about the relationship between these theses may be briefly made here. First, on certain interpretations, they are not inconsistent: one could rationally endorse each thesis. For instance, if a person's right is simply their being situated such as to be owed a duty with a certain content, then Duty and Right continuity are not competitors. Second, on certain interpretations, they do not entail each other. For example, if one believes that not all duties correlate with rights, and that those duties' breach may give rise to compensatory duties, then it will be important to defend Duty continuity as a thesis distinct from Right continuity. It may be suggested that since rights and duties are simply special kinds of reason for action that Duty and Right Continuity are entailed by Reasons continuity. ${ }^{9}$ As formulated, however, Reasons continuity refers to the reasons which ground a duty. Even if a duty is reason, it is not a reason which grounds the duty which is constituted by that reason. ${ }^{10}$ There is a related idea which does, however, entail the other two theses. This could be formulated thus: 11

\footnotetext{
7 See especially A Ripstein, Private Wrongs (HUP, 2016) 248: 'Rights survive their own violation...'.

${ }^{8}$ Gardner (n 5).

${ }^{9}$ On one view, a duty is a protected reason: J Raz, Practical Reason and Norms (OUP, 1999), 2.3.

10 A duty may ground further duties in combination with certain requirements of practical rationality.

11 J Raz, From Normativity to Responsibility (OUP, 2011) 189-192.
} 
Conformity principle. If an agent fails to conform to a reason, and that reason persists, the person has a reason to come as close to conformity to the reason as possible.

I believe that the Conformity principle is true and entails the continuity theses. Nonetheless, I will proceed to consider each continuity thesis separately partly since there may be reasons to endorse the narrower continuity theses, and partly because the theses have been offered as distinct in the literature.

For any of these theses to be established, it must be shown that the prebreach normative feature relied upon - the duty, the reason, the right persists after its breach and now justifies a compensatory duty, or it must be shown that this feature justifies both the pre-breach duty and postbreach duty to compensate. It will be convenient to consider Duty continuity and Reasons continuity first before turning to Right continuity. The discussion will also be primarily focussed upon compensation in respect of interference with a person's bodily rights. In Section 5, I briefly consider the extent to which these explanations can be extended beyond bodily rights.

Before moving to my defence of continuity thesis explanations of duties to compensate, it may be helpful - in order to see what is at stake in this defence - briefly to contrast this kind of explanation with others.

Consider, first, then, the idea that compensation is justified as a matter of 'corrective justice'. This idea itself merely postpones the question of why it is a requirement of justice that compensation is owed for harm caused by wrongdoing. The explanation may simply be that justice demands that a wrongdoer conform to their continuing duty, or the continuing reasons for their original duty. ${ }^{12}$

Next, consider the idea that compensation is required, when it is, in order to undo the impairment of a relationship between the wrongdoer and the victim. ${ }^{13}$ It is possible to describe each of us as in a moral relationship with every other member of the moral community. This relationship seems constituted by a set of reciprocal duties such as duties not wrongfully to harm each other. To impair this relationship seems then simply to be to breach the duties that constitute the relationship. The question then arises why the breach of the duty should give rise to a duty to compensate. It takes us little further to say that the breach (which is or was constitutive of the relationship) must be 'repaired'. Why? Even if this theory is restricted to special relationships which are constituted not simply by a set of reciprocal duties (but also certain attitudes and patterns

12 The responsibility account mentioned below is sometimes offered as a deeper account of why corrective justice demands compensation.

${ }^{13}$ L Radzik, Making Amends: Atonement in Morality, Law, and Politics (Oxford University Press, 2009). 
of conduct), it remains unclear why the impairment of such a relationship calls for compensation.

Third, it has been argued that compensation is morally required in order to express sincere regret for the wrong. ${ }^{14}$ There are two problems with this as a general account of duties to compensate. Intuitively it is sometimes permissible to take a wrongdoer's resources to compensate the victim of the wrong even if the wrongdoer is incapacitated such that they are unable to express regret. This permission is naturally explained by the existence of an independent duty to compensate. Furthermore, the reason why compensation can be taken, when other conditions are met, to express regret seems to be explained by the prior fact that doing so is morally required. The reason why a heartfelt apology may sometimes not be enough is precisely because further, as yet unmet, moral compensatory duties still call for conformity.

Fourth, it could be argued on rule consequentialist grounds that moral duties to compensate will make things go best. If people are under such duties, it will incentivise them to conform to their duties not to wrongfully harm. This is one way of interpreting Pufendorf's view that without duties to compensate, duties not to injure would be an empty requirement. ${ }^{15}$ It seems odd, however, that the content of moral duties is so contingent upon people's imperfect motivational willingness not wrongfully to harm other people: were moral agents more motivated to conform to their duties not to harm in virtue of the aptness of so acting, then there would be no moral duties to compensate. While not conclusive against such a view, this is an unfortunate implication.

Fifth, compensatory duties are sometimes justified on the basis of a person's 'responsibility' for a harm. On its own, it is unclear how responsibility justifies a compensatory duty. An argumentative bridge is needed from ' $\mathrm{X}$ is [causally, attributively, or otherwise] responsible for a harm' to ' $\mathrm{X}$ is under a duty to compensate for that harm'. A plausible bridging argument is that responsibility is relevant to the fair allocation of harm between persons. This is one role the concept of responsibility plays in arguments about the justification of liability to defensive harm. ${ }^{16}$ More generally, it is widely accepted that responsibility, in some thicker sense than causal responsibility, is relevant to the fair allocation of benefits and burdens. I do not fully reject this view, but I argue later that there are

${ }^{14}$ E Encarnacion, 'Corrective Justice as Making Amends' (2014) 62 Buffalo LR 1.

${ }^{15}$ De Officis Bk I, Ch VI.

16 J McMahan, 'Self-defence and the Problem of the Innocent Attacker' (1994) 104 Ethics 252, 259: "[I]n cases in which a person's [wrongful] action ... has made it inevitable that someone must suffer harm, it is normally permissible, as a matter of justice, to ensure that it is the [wrongdoer] who is harmed rather than allowing the costs of his wrongful action to be imposed on the [other(s) on whom they might instead have fallen]”. See also SH Perry, 'The Moral Foundations of Tort Law' (1992) 77 Iowa Law Rev 449. 
Legal Theory - Revised Submission

situations where a continuity account seems necessary to explain the unfairness. ${ }^{17}$

\section{Duty continuity}

Consider, again, Arm. If Duty continuity is to explain the existence of a compensatory duty in this case, then it must identify a duty owed by the wrongdoer which continues in existence after that duty has been breached and now requires compensation, or a duty which justifies both the duty breached and the duty to compensate. I will consider three candidate duties: (a) the duty not to damage another's bodily functioning by one's action without justification; (b) the duty not to disrespect another's bodily rights without justification; (c) the duty not to be a causal source of damage by one's action to a person's bodily functioning without justification. Each duty is an all-things-considered duty: if the agent breaches the duty, they behave impermissibly. I consider the complications which arise with a pro tanto duty understanding of Duty continuity later. ${ }^{18}$

Consider, first, (a). The first question is: does (a) continue after its breach? In one sense, the duty does continue: it continues in the sense that the wrongdoer is still under (a) in relation to future conduct in relation to the victim. But in another sense, the duty does not. If the arm is irreparably damaged, then the duty not to damage the arm does not continue. Just as there is no duty not to kill the killed, or to keep in confidence information that is no longer confidential, there is no duty not to damage an irreparably damaged arm (in the precise respect in which it was irreparably damaged).

An objection to this last point is that it would be 'absurd' if breaching a duty were a mode of discharging it. ${ }^{19}$ Three responses may be made. First, this objection gains intuitive purchase by using the word 'discharge' rather than 'cause not to exist'. Discharge means 'fulfil'; clearly, to breach is not to fulfil a duty. There is nothing absurd about the idea that a person who kills their friend causes an abrupt cessation of (some of) the duties of friendship. ${ }^{20}$ Second, once it is realised that the duty continues in the first sense identified in the last paragraph, the counterintuitiveness of the claim is reduced further: there is a sense in which the duty continues. Third, if breach of a duty gives rise to a new duty to compensate, then the idea that the wrongdoer benefits from breaching the duty, which may be at the root of the appearance of 'absurdity', evaporates.

The second question, then, is: does (a)'s continued existence in the first sense justify a duty to compensate for the breach? It does not. If the wrongdoer is subject to a continuing duty not intentionally to damage the

17 Below, Section 5.

18 Section 5.

19 E Weinrib, Corrective Justice (OUP, 2012) 91.

${ }^{20}$ Friends might have special duties to honour the memory of their friends and so on, in some cases perhaps by pursuing their incomplete projects. 
victim's arm in relation to future conduct, it is obscure how conformity to this duty could require, now, compensation in respect of the damage done. Compensating will not amount to not damaging the arm.

Consider now (b): the duty not to disrespect the victim's rights over his body without justification. This is possibly how Weinrib understands the relevant continuing duty in this passage:

The defendant's breach of duty did not of course bring to an end the duty with respect to the plaintiff's right, for, if it did, the duty absurdly - would have been discharged by its breach. To be sure the specific action required of the defendant has been transformed by the defendant's tort. Just as the plaintiff's right is no longer embodied in the specific object, which has been destroyed, but in an entitlement to receive the object's equivalent from the defendant, so the defendant's duty is no longer to abstain from its destruction, which has already taken place, but to provide the plaintiff with the object's equivalent. The specific action that the duty requires is different, but the defendant is not under a different duty. ${ }^{21}$

On this view, the duty that survives is not identified, then, with the duty not to damage or injure (though Weinrib sometimes seems to say this). ${ }^{22}$ It is a more abstract duty. It might be formulated as a 'duty to respect the victim's right to their body'. ${ }^{23}$ Ex ante, the duty of respect for another's right requires non-interference with the object of the right. Ex post, the duty of respect requires compensatory action. On this view, there is a single, continuing, duty with different incidents at different times, the changing requirements of the duty changing with the alteration in circumstances effected by the breach.

Once the relevant duty is defined so abstractly as a duty not to disrespect the victim's rights, however, it becomes unilluminating as an explanation of the compensatory duty. Simply stating that respect for the victim's right after infringing it requires compensation leaves us largely in the dark as to why this is so. This view is not necessarily false, but it requires further elaboration.

Consider now (c), the duty not to be a causal source of damage by one's act to a person's bodily functioning without justification. This duty is different from duty (a). There is a difference between damaging a person and being a causal source of damage. If A breaks B's arm, then A damages

${ }^{21}$ E Weinrib, Corrective Justice (OUP, 2012) 91.

22 Weinrib (n 20) 90: 'At its most general, having a right in private law means that the right-holder is normatively so connected to the object of the right that another person is under a duty not to interfere with that object'. This suggests that what survives is the duty not to interfere.

${ }^{23}$ Drawn from Weinrib (n 20) 90: 'Even if the object no longer exists as a physical entity, the parties continue to be related to each other through the object's normative connection to the plaintiff and the consequent duty on the defendant to act in conformity with that connection. 
$\mathrm{B}$ at $t$. At $t+1$, A's relationship to B's damage - the broken arm - is that A is a causal source of the negative state that constitutes B's damage. In not repairing B's damage, in so far as it is possible to do so, then B continues to be a causal source of this damage. In Arm, A has breached duty (c) by removing B's arm: A has been a causal source of damage to B's bodily functioning. But A can still conform to duty (c). Whether B will suffer damage to B's bodily functioning in the future as a result of A's conduct depends, let us suppose, upon obtaining a substitute arm. A can make it the case that $\mathrm{A}$ is not a causal source of damage to B's bodily functioning in the future by providing the means to obtain the arm.

Let me elaborate further on this duty by explaining in more detail the notions of 'damage' and 'causation' it employs. To be a cause of damage is to negatively affect the good in a person's life. This could occur by causing a physical change in a person which gives rise to 'bads' for that person for instance, pain resulting from a broken arm. This physical changesay, a broken arm - may persist through time, and along with it, the accompanying pain. So 'damage' is something which can persist through time. Damage need not consist in a metaphysically 'positive' state, however. It may consist in a continuing deprivation - the absence of a good or set of goods in a person's life. It is possible to be a continuing cause of a person's deprivation - the absence of a good for them, as much as it is possible to a cause of a continuing 'positive' bad state.

One can also be a continuing cause of something through time. If you put a weight that I cannot lift on my toe, and leave the room, intuitively, all through this period you are causing me, or are a causal source of, my pain. Similarly, the thought goes, if you put me in a physical state which will have various negative consequences for me that I cannot 'lift' without compensation, then you are a continuing causal source of those negative consequences. Now, it might be said that these claims rely upon a controversial notion of causation. After all, in a simple counterfactual sense, the damage in the toe example depends upon the acts which led me to be in your presence at that time, so I might be said to be a cause of my own damage. The relevant notion of causation intended in duty (c) is 'thicker' than a simple counterfactual account, however. It is rather the notion of causation, or a similar notion, to that invoked by the law (and, some claim, ordinary thought) when it describes a poisoner as causing a person's illness, and not the latter's presence in the poisoner's vicinity. ${ }^{24}$ One might worry that this notion of causation already implicates normative judgments about duties to compensate, and so cannot be employed in an explanation of duties to compensate without circularity. This is a legitimate concern. It seems to me, however, that the relevant notion of causation is not so fully moralised as to require us already to have an account of who has a duty to compensate in order to apply it. Suppose that I mow the grass in my garden. If we ask - what caused the grass to be cut? - it would be odd to think that 'oxygen' was the answer,

${ }^{24}$ For one possible analysis of this notion of causation, see HLA Hart and T Honore, Causation in the Law, $2^{\text {nd }}$ edn (OUP, 1985). 
even if oxygen is a necessary condition of my grass-cutting. But the distinction being drawn here between a background condition (oxygen) and a cause (say, my perception that the grass is too long) is not obviously explained by a moral judgment about the relevant duties in the situation.

An objection to this defence of Duty continuity is that it does not justify a duty of compensation. Consider again Arm where the arm has not yet been acquired. If A provides B with the means to acquire the arm, this does not compensate $\mathrm{B}$, but provides $\mathrm{B}$ with the means to prevent future damage occurring. Compensation, it may be objected, involves placement of a person in the position they would have been in had no breach occurred through negating or counterbalancing damage. In Arm, the damage - the continuing loss of bodily functioning - is not being negated or counterbalanced, but prevented from occurring. ${ }^{25}$ If a court ordered a person to build a wall to prevent future flooding after a wrongful flooding, this would not be described as an order to compensate. My tentative reply to this objection is that in many cases, the distinction between prevention and compensation is unclear and either description is apt. In Arm, A's wrongful act puts $B$ at risk of future harm. In providing $B$ with means to acquire the arm, A could be said to be restoring B to B's no-breach position by reducing the risk that B currently (wrongfully) faces. In this way, the preventive measure can be understood as restorative.

In sum, then, Duty continuity can justify a compensatory duty if the following conditions hold: (a) a person is subject to a duty not to be a cause of a state of affairs (for example, that a person is damaged); (b) whether the state of affairs persists due to the person depends on whether compensation is provided (c) if the state of affairs obtains without compensatory action being taken by the person subject to the duty, the person will be said to be a cause of the existence of the state of affairs.

(3) Reasons continuity

This section proceeds first by explaining Reasons continuity. It concludes by arguing that there is no advantage to Reasons continuity over Duty continuity. Consider again, then, Reasons continuity:

Reasons continuity: the reason or reasons grounding the duty breached continue post-breach, and next-best conformity to those reasons may require compensation. ${ }^{26}$

On this view, the continuing normative entity is a reason or set of reasons. More precisely, it is the reason(s) which grounded the duty breached.

25 On the distinction between negating and counterbalancing harm, see A Slavny, 'Negating and Counterbalancing: A Fundamental Distinction in the Concept of a Corrective Duty' (2014) 33 Law and Philosophy 143. ${ }^{26}$ Again, I will consider here reasons which ground all-things-considered duties first, before considering pro tanto duties later: Section 4 . 
What does it mean for a reason to ground a duty? Proponents of this view are not clear on this issue. ${ }^{27}$

One possibility is that a duty is constituted by certain reasons: a reason to do $\mathrm{X}$, or set of reasons to do $\mathrm{X}$, and a reason not to act on certain reasons against X-ing; or a duty is constituted by the balance of reasons favouring $\mathrm{X}$-ing. This doesn't seem, however, to be what was intended by John Gardner, who offers the most sophisticated defence of Reasons continuity. ${ }^{28}$ Gardner writes of the reasons which serve as the 'rationale' of a duty or which 'justify' a duty. ${ }^{29}$

Another possibility is that by grounding reasons one really means grounding values. On this view, the value of well-being for example, in conjunction with certain other facts, grounds duties not to set back others' well-being. Values (e.g. the value of human well-being) are not usually individuated by the act tokens which serve, promote, or respect those values. By contrast, reasons are individuated by the act tokens (a reason to eat green beans), or at least act-types (a reason to promote my health), which they are reasons for or against. Although we might speak of the 'reasons of love', where it seems that reasons are not tied to any particular actions, what this expression probably means is 'the reasons to do particular acts to which the value of love gives rise'. In what follows I will assess the idea that there are reasons to do certain things that either constitute or ground duties to do those things, which continue. ${ }^{30}$

Consider, again, our first question for any continuity thesis: does the normative entity - here a reason - continue after the breach of duty? A possible theoretical argument why reasons 'stick around' after acts which do not conform to those reasons is that, otherwise, there is no sense in which there was a reason in the first place. Compare Ripstein's argument that if rights didn't survive their violation, there would be no sense in which one had a right in the first place. He writes: 'If I could unilaterally dissolve your entitlement to constrain my conduct, there would be no sense in which you were entitled to constrain it'. ${ }^{31}$ This argument is not fully persuasive. A person who denies the existence of duties to compensate does not seem to be logically required to deny the existence of a primary duty not to injure. She can say: yes, I wronged you by breaching a duty not to injure, but that is past history now. She does not thereby deny that there was any 'sense in which you were entitled to

27 The issue is not probed in much detail in Gardner (n 5).

${ }^{28}$ See Gardner (n 5).

${ }^{29}$ See Gardner (n 5), 60- 61. Or perhaps Gardner's view is that reasons part constitute and justify duties.

30 See generally Gardner n 5.

${ }^{31}$ Ripstein (n 4) 248. Similarly, Weinrib (n 20) 91: 'The defendant's breach of duty did not of course bring to an end the duty with respect to the plaintiff's right, for, if it did, the duty - absurdly - would have been discharged by its breach.' 
constrain [her conduct]'. The fact that a person can cause a duty not to exist does not entail that the duty not exist. This becomes clearer when we consider arguably the primary function of a duty. If one has a duty, certain reasons are excluded from the set of reasons one can rely upon in deciding what one ought to do. This function of a duty can be performed even if the duty is brought to an end upon breach. The fact that a duty will cease to exist if it is not conformed to has no impact upon whether the reasons excluded by the duty are excluded at the time of the breaching action. It will still be impermissible (and make no sense) to reason in this way: 'I may breach this duty because it will cease to exist upon breach'.

A better argument is provided by Gardner. His argument for the conclusion that reasons may continue after breach seems to be based upon an inference to the best explanation. He presents an example from Neil MacCormick in which a parent promises their child to take them to the beach on Saturday. ${ }^{32}$ The parent as a result of an emergency cannot do so. Intuitively, Gardner claims, the parent will feel still constrained by the promise, albeit that that it is now impossible to comply with the promise. The best explanation for this phenomenon is that the reasons for the promise - the conferral of pleasure, for instance - continue to exist and call for conformity. This is what best captures the sense, he claims, in which the duty leaves a rational 'trace'. Call this the 'intuitive' argument.

Gardner's argument can be bolstered with a simple observation: if one has a reason to $\mathrm{X}$ at $\mathrm{t}$, at $\mathrm{t}+1$ it is still possible to $\mathrm{X}$, and the reasons why (which may be a more general reason that entails $\mathrm{X}$-ing at $\mathrm{t}$ ) one had the reason to $\mathrm{X}$ continue to obtain at $t+1$, it is difficult to understand why the reason to $\mathrm{X}$ disappears entirely. Reasons to $\mathrm{X}$ cease to exist by it becoming impossible to $\mathrm{X}$ or by the reasons to $\mathrm{X}$ being cancelled in virtue of a change in the circumstances sustaining the reason to $\mathrm{X}$. It may be, of course, that at $t+1$ there are new countervailing reasons not to $X$. But these do not eliminate the reason to $\mathrm{X}$, they simply compete with it. Call this the 'theoretical' argument.

An important objection to the claim that the grounding reasons for a duty continue after the duty's breach is made by Smith. In his view, the 'ordinary understanding' of duties and reasons poses a problem for the claim that the same reason continues. He gives the example of a person destroying another's chair:

In the ordinary understanding, then, your duty not to interfere with my chair (or the reasons underlying that duty) is contingent on the chair's existence. If the chair does not exist, for whatever reason, then it makes no sense to speak of a duty not to interfere with the chair or of reasons not to interfere with the chair. ${ }^{33}$

32 Gardner (n 5) 28.

33 S Smith, 'Remedies for Breach of Contract: One Principle or Two?' in Letsas and Saprai (eds) Philosophical Foundations of Contract Law (Oxford University Press, 2014) 348. 
Smith is correct: happily, there is no reason not to interfere with nonexistent chairs. The reason that continues, if any reason does in Smith's example, cannot, then, be identified as such. But Smith neglects the possibility that the reason which continues is a reason which generates one reason ex ante (a reason not to interfere) and a different reason (a reason to compensate) ex post. This feature of reasons - that they can generate further reasons - is commonplace. ${ }^{34}$ Compare: I have a reason to maintain my health. This reason gives rise to many other reasons: a reason to eat green beans, a reason to go for a run, a reason to drink less beer. I have reason to do these acts in virtue of my reason to maintain my health because these acts contribute towards conformity to that reason. A possible reason that continues in Smith's example is a reason to maintain the level of a person's existing resources. This reason generates a reason not to interfere ex ante and a reason to compensate ex post.

Whether such a reason exists is not crucial for the success of Reasons continuity as a thesis about compensatory duties in general. For Reasons continuity to be successful, all that needs to be shown is that there is a significant class of compensatory duties that can be explained by it. It is open to serious doubt whether there are always reasons for persons to maintain other people's holdings at their existing level. But it is far less doubtful that there are no genuine continuing reasons in Arm. Suppose, plausibly, that part of the justification of the duty not to damage another's body by one's action is the reason not to make a person's body worse off in how it functions. If you cause my arm to be destroyed, and it is possible to restore the functionality of my body by providing me with a prosthetic arm (or the means to obtain one), then it is still possible to conform to this reason, by providing the arm or the means. Here one continuing reason generates reasons to perform different actions: the reason not to cause a person's body to be worse off by your act generates a reason not to damage the body at all, then a reason to restore its functionality afterwards. So there are at least some important cases where the relevant reasons do, contra Smith, persist. But they need to be described at an appropriate level of abstraction.

Now consider two objections. The first objection is that I fall foul of the objection I made to Weinrib's account of Duty continuity - namely, that Reasons continuity becomes so abstract as to be unilluminating. There is a difference, however, between merely asserting that respect for a person's right to $\mathrm{X}$ requires such and such at different times (ex ante: noninjury; ex post: compensation) and explaining how a chain of reasons generates a compensatory duty. Consider giving a person advice: 'respect the right you have breached' is less informative advice than 'the right you violated was based upon maintaining a person's healthy functioning of their body - you can still conform to that reason by providing the means to restore that functioning'.

The second objection is that, if one has a reason not to $\mathrm{X}-$ say, a reason not to worsen a person's bodily functioning - and one has worsened their

${ }^{34}$ Gardner (n 5), 60. 
bodily functioning irreparably to some extent, then the reason not to worsen cannot continue, because it is now impossible not to worsen their bodily functioning. At best, the reason which continues is a reason to do the next best thing to not worsening a person's bodily functioning, which is to minimise the extent of the worsening. But a reason not to $\mathrm{X}$ and a reason to do the next best thing to not X-ing are different reasons. This objection is valid. It should probably be conceded that the reason that exists post-breach is either the same or a very similar reason. In the latter case, there is strictly no continuity in the sense of the persistence through time of a single reason. But there is continuity in the sense that the postbreach reason has a very similar content, and justificatory basis, to the pre-breach reason - the reason not to harm at all is very similar to the reason not to harm in part.

If the intuitive argument and the theoretical argument are accepted, then we ought to believe that, at least sometimes, the grounding reasons for a duty continue after the duty's breach. The next question is: do the continuing reasons ever generate a duty to compensate? Hopefully, it is relatively clear now how this is possible, once the relevant description of the continuing reason has been identified. If the continuing reason in Arm is the reason not to worsen a person's bodily functioning, then, in light of the acts constituting the breach - damaging the arm - conformity to this reason requires that one takes steps to prevent the worsening of functioning that the damage is likely to cause. One such step is the payment of monetary compensation. If one of the grounding reasons of duties not to damage others' bodies is a reason not to worsen significantly a person's well-being more generally, then, to the extent the breach has reduced or poses a substantial risk of reducing their well-being, then one has a reason to provide monetary compensation to the extent that will prevent a worsening of well-being. Notice that the continuing reason can justify radically different actions pre-breach and post-breach. The reason not to worsen significantly a person's reputation justifies a duty not to defame ex ante. Ex post it could require significant monetary compensation - to the extent that the payment of this compensation conveys the message to others that the statement made is false and thereby restores the person's reputation.

Does Duty continuity enjoy an advantage over Reasons continuity? There seem to be at least two reasons to argue for Reasons continuity over Duty continuity. First, there is what we can call the individuation argument: according to Gardner, duties are individuated by the act they require, while reasons do not necessarily require specific actions, but can ground a variety of actions. So if a person is required to do act $\mathrm{A}$ and act $\mathrm{B}$, the person has two duties. But it may be that the reason which justifies both duties is the same. Suppose, for example, that you push me off a cliff. Happily, philosophical luck has it that you can press a button which will cushion my fall, preventing my death. On Gardner's view, you would have two duties in this example: a duty not to push me off the cliff, and a duty to press the button. But, plausibly, the same reason justifies both duties: the reason not to cause my death by your act. This reason requires you not 
to do acts that substantially risk my death, and then acts which prevent that risk materialising.

It seems to me, however, that we can meaningfully speak of general duties which generate more specific duties at different times. For example, if I have a duty of care towards you when driving, this general duty might require me to do one thing when I am driving on a busy road, but something different when I am driving down a country lane. Similarly, if I have a duty not unjustifiably to be a causal source of damage to you, this general duty may entail more specific duties at different times. Applied to the cliff example in the last paragraph, it generates a duty that you not push me off the cliff, and then a duty to press the button to protect me. Once we see this, it's not clear that there is a deep contrast between Reasons continuity and Duty continuity. The 'reason' to which Reasons continuity appeals may just be a general mandatory and categorical reason, such as the reason not unjustifiably to be a causal source of damage to a person. This general reason generates requirements to do specific actions at different times, as the facts to which the duty attaches change.

A second argument in favour of Reasons continuity over Duty continuity might be that there are duties to compensate which are more readily explained by Reasons continuity. Suppose A unjustifiably breaches A's promise to B to pick B up from the airport, causing B to take a much more expensive ride home. It is plausible that $\mathrm{A}$ owes a duty to compensate B for B's loss. Is there a duty that A has breached which continues so as to justify a duty to compensate? Any duty which includes 'being a cause of loss' in its content seems unlikely to be convincing. This is because the duty breached is the duty to perform the promise, and this duty is not a duty whose content includes 'not causing loss'. A promise can be breached without causing any loss. For example, suppose you promised to pick me up from the airport and fail to do so, but, as it turns out another friend is passing by chance and takes me home. It's still the case that you breached your promise. By contrast, it might be argued, Reasons continuity can identify a reason which justifies the duty to keep the promise and the duty to compensate. This is a more promising strategy for a defender of the superiority of Reasons continuity. But it is not clear that it succeeds. First, although the primary duty of a promisor is to keep the promise, it is plausible that the promisor also has a duty not to be a cause of worsening of the promisee's position by breaching the promise. Duty continuity could appeal to this duty to explain the compensatory duty in the promise case. Second, while the idea that there is a single reason justifying the promissory duty and the compensatory duty sounds plausible, the devil is in the detail. It may be that any reason identified for instance, a reason not to damage the socially valuable institution of promise-keeping - can also be relied upon by the defender of Duty continuity.

(4) Right continuity 
Right continuity can be understood in at least two ways corresponding to different understandings of the notion of a moral right. If a moral right is simply the Hohfeldian correlative of a moral duty, then everything I have said about Duty continuity can simply be transposed into the language of Right continuity. Every case where Duty continuity justifies compensation is also a case where Right continuity, on a Hohfeldian understanding of rights, justifies compensation, too. This is because rights are simply the logical correlatives of duties. ${ }^{35}$

Moral rights can alternatively be understood, with Raz, as interests sufficiently important to justify duties upon others. ${ }^{36}$ Consider a person's interest in bodily integrity. This is sufficiently important to justify certain duties of non-injury upon others. Plausibly, this interest is also sufficiently important to justify a duty to compensate for bodily injury once it has been interfered with, at least so far as conformity to that duty alleviates the bodily injury.

This version of Right continuity is true, but it is also relatively unilluminating in the same way as Weinrib's version of Duty continuity is unilluminating. A person's interest in their bodily integrity is something of sufficient importance to justify duties in others, but it requires further elucidation why it justifies a duty of compensation, and a duty of compensation in the injurer in particular.

The elucidation could be developed as follows. If an interest is sufficiently important to justify negative duties of non-injury, it must also be sufficiently important to justify at least some positive duties to promote the interest. This becomes plausible when we think about the stringency of some negative duties. Negative duties may require us to bear very significant personal costs to avoid breaching them. If I knowingly drive a dangerous vehicle which malfunctions and endangers your life, I may be required to take evasive action to protect you even if that involves the loss of my own life. The stringency of negative duties in relation to people's bodies implies that people, and their bodies, are of great moral significance. If so, it is highly plausible that the interests which generated those stringent negative duties must be such as to justify some positive duties, too.

A more difficult problem is to explain why Right continuity on the Razian understanding of rights justifies a duty of compensation in the injurer, and the particular character of that duty. The damaged interest in bodily integrity could be promoted by a wide range of people - why pick on the injurer? Further, the injurer's duty is not like the moral duty of easy rescue - a duty that requires a person to promote a person's interest that exists between everyone. The compensatory duty links only the injurer and the victim, and it differs in its stringency from a duty of easy rescue. While I may be required to bear relatively small costs to protect a stranger from a risk I did not create, compensatory duties are not like

35 See generally WN Hohfeld, Fundamental Legal Conceptions (Yale UP, 1919).

36 J Raz, The Morality of Freedom (OUP, 1986), 166. 
this. The injurer's duty to compensate is intuitively more stringent than the duty of a third party unconnected with the injury. This is reflected in legal practice: a court may authorise a person's assets to be seized and sold in order to satisfy a massive compensatory debt, but duties of easy rescue, so far as they are legally enforced at all, require only minimal costs to be borne for the sake of others.

A part of the answer might be the injurer's responsibility for the injury to the interest constitutive of the right. The person's interest in bodily integrity, the fact that compensation would promote that interest, and the fact that the injurer is responsible for the injury to the interest, generates a moral duty in the injurer to compensate. The problem with an appeal to the injurer's responsibility, for a defender of a continuity thesis, however, is that the injurer's responsibility is apparently not a feature of the prebreach normative situation. The injurer's duty not to injure was not justified or constituted by their responsibility for the injury suffered. Responsibility, in the relevant sense, concerns the connection between the injurer, their conduct, and the injury. This connection did not exist prior to the injury, and so could not justify the duty of non-injury.

A possible response on behalf a defender of Razian right continuity is that the facts in virtue of which an injurer counts as responsible, when they are, are facts that pre-exist the injurer's responsibility. For example, suppose one holds that a person is only responsible for an outcome if the person had a reasonable opportunity to avoid producing that outcome. The facts which make it the case that such an opportunity exists are facts antecedent to the injurer's responsibility. ${ }^{37}$ The problem with this response is that many people may have a reasonable opportunity to avoid producing an outcome, and yet only, or at least normally, the person who actually produced it is under a duty to compensate for it.

A more persuasive response to the difficulty of accounting for the fact that the injurer is in a special position when it comes to compensatory duties might be as follows. The Razian account, much like Duty continuity, can point to general duties justified by the interest that constitutes the right. The right to bodily integrity might, in this vein, be argued to justify a general duty not unjustifiably to be a causal source of damage to a person's body, with that duty, in turn, requiring a particular person to perform different actions at different times. A further, secondary response is that a person's right - their sufficiently important interest on this account - is what drives the practical conclusion that the injurer has a duty to compensate, even if the injurer's responsibility also enters as a reason for that duty's existence.

In sum, Right continuity is also defensible. On a Hohfeldian reading, it has the same virtues as Duty continuity. On a Razian reading, it justifies compensatory duties, albeit in doing so, it may move closer to an account of compensatory duties that makes responsibility for an infringement of a

37 This kind of move (albeit not in defence of a continuity thesis) is made in E Voyiakis, Private Law and the Value of Choice (Hart, 2017). 
right a positive reason for a compensatory duty, rather than a mere background condition of its existence. ${ }^{38}$

(5) Limits of the compensatory duties generated by continuity theses

The discussion so far implies that continuity theses explanations of compensatory duties are successful in cases of (a) breaches of all-thingsconsidered duties, (b) not to be a cause of a damage to a person's body, (c) if the compensation will contribute to the eradication or mitigation of the damage. If these are the limits of the continuity explanations, then they explain a very small category of compensatory duties. In this section, I argue, in relation to (a) that Duty and Reasons continuity cannot straightforwardly be extended to pro tanto duties. However, I propose that, with modifications, the better version of Duty continuity is one that extends to pro tanto duties. In relation to (b), I argue that Duty continuity can explain compensatory duties in relation to interference with property in many cases. In relation to (c), I argue that, supplemented by a consideration of fairness, Duty and Reasons continuity can explain duties to compensate in cases where the damage has already been repaired by the victim or a third party.

\section{Pro tanto duties}

Consider this case of justified damage:

Dock. A wholly unforeseeable storm arises while A is sailing on A's boat. The only way for A to prevent himself being swept away by the storm to certain death is by anchoring to, and thereby damaging, B's dock.

The generally accepted view in the literature appears to be that, although A acted permissibly, A ought nonetheless to compensate B for the damage done to the dock. If Duty and Reasons continuity are limited to all-thingsconsidered duties then they cannot explain this result: A had no such duty in the circumstances. A natural suggestion, then, is to suppose that the better versions of these theses concern pro tanto duties. Then Duty and reasons continuity can explain A's duty on the basis that the reasons which constituted A's pro tanto duty not to damage the dock continue after the breach of that duty. These reasons were not cancelled by the damage to the dock (as they probably would have been if the dock owner had consented to the damage $\left.{ }^{39}\right)$. They were merely outweighed and persist, calling for conformity; the call is answered by compensatory action.

38 See below at X, for further elaboration of this contrast.

${ }^{39}$ It is plausible that, in some cases, the injurer ought to compensate the owner in Dock even when the owner consents. This might be an incident of a duty of gratitude. If the owner only consents because she knows that this will allow A to suffer a more painful death in the future, it is less 
So far, so good. But not every case of justified harming gives rise to a duty to compensate. Here are two examples. First, an innocent does not owe compensation to a highly culpable unjust attacker for harm imposed upon the attacker in justified self-defence. Call such a situation Self-defence. Yet, if Self-defence is properly considered a case in which the pro tanto duty or general reason against harming the attacker is outweighed by a countervailing consideration, it seems that, by virtue of the continuity theses, there is a pro tanto duty to compensate the unjust attacker. Yet it seems (very) implausible that the victims of highly culpable unjust attacks owe their attackers compensation for harm justifiably imposed in selfdefence. Second, consider a variation on Dock:

Dock 2. A is struck by lightning while sailing and becomes unconscious. The only way to prevent A being swept away to certain death is for C to anchor A's boat to B's dock, thereby damaging B's dock.

Here the pro tanto versions of the thesis would entail that $\mathrm{C}$ has a pro tanto duty to compensate B. Again, this is counterintuitive. It is plausible that $\mathrm{B}$ would have been under a moral duty to allow A to damage the dock, if that were A's only means of survival. If $\mathrm{C}$ has a pro tanto duty to compensate $\mathrm{B}$, then $\mathrm{C}$ is under a duty to compensate $\mathrm{B}$ for damage which $\mathrm{B}$ would have been under a duty to allow anyway.

This is a serious and undiscussed problem for continuity thesis justifications, which are often formulated in terms of pro tanto duties. ${ }^{40}$ Here are three possible solutions for a defender of the continuity thesis. First, it might be argued when a person is liable to self-defence, this cancels the reason against harming them and does not merely outweigh it. On this view, the reason disappears, just as the reason to perform a promissory duty which has been waived by the promisor disappears. This is perhaps one implication of the idea that an attacker 'forfeits' their rights in such circumstances. By contrast, in Dock, B has done nothing to forfeit their right.

Second, it could be that while there is a continuing reason in selfdefence cases for compensation, this reason is outweighed by a countervailing distributive consideration. The culpable wrongful attacker is entirely responsible for the harm that befalls them. Given this overwhelming responsibility for their own harm, it is fairer that they bear its costs. In short, while there is a reason to compensate, this reason is outweighed by the unfairness that would occur if the victim were saddled with the costs of A's culpable wrongdoing.

clear that A owes the duty; this intention-dependence is explicable if the duty is sourced in gratitude.

40 See Gardner (n 5). 
A third possibility is simply to concede that the continuity theses ought to be restricted to breaches of all-things-considered duties, and propose an alternative explanation for compensation in cases of justified damage.

All three solutions are problematic. The first solution excludes a duty to compensate in Self-defence, but not in Dock 2, since there is no forfeiture in Dock 2 either. ${ }^{41}$ The second solution fails to explain the difference between Dock and Dock 2: it cannot be said that the victim is fully responsible for its damage in Dock 2, but not Dock. The third solution requires a continuity theorist to produce an alternative explanation of compensatory duties in justified damage cases. This might turn out to be possible, but it seems unpromising. I can think of two possible alternative explanations. One points to the fairness of requiring A to compensate B because of the benefit that A obtains in Dock, but not in Dock 2. Why should this benefit have moral significance? One possibility is that, if A compensates $\mathrm{B}$, this is a fairer distribution of burdens between $\mathrm{A}$ and $\mathrm{B}$ : by requiring $A$ to compensate $B$, we make $A$ no worse off than $A$ would have been had A not damaged the dock, and we make B no worse off. This argument needs to provide a reason, however, for selecting as the appropriate baseline the position where $\mathrm{A}$ does not damage the dock. If $\mathrm{A}$ is not morally required not to damage the dock, then, absent some further explanation, it is not clear why fairness supports a return to this baseline. If, however, A has a reason not to worsen B's property holdings which continues, then this reason explains why such a baseline might be appropriate. In this way, the fairness argument seems partly parasitic upon a continuity explanation. Furthermore, the fairness argument suggests that fairness would be equally satisfied by several unrelated persons bearing the burden of compensating B if they could do so at minor cost. Yet it seems intuitively that A has a special reason to compensate B. Finally, this proposal faces the problem that, intuitively, A would still owe compensation to B if A damaged B's dock, reasonably believing that this would prevent his being severely injured, but it so happens that he is severely injured anyway. Here A is not benefitted. ${ }^{42}$ This intuition might be supported by a parallel self-defence case: if A has a reasonable, but mistaken, belief that $\mathrm{B}$ is attacking $\mathrm{A}$, and is threatening force against $\mathrm{B}$, $\mathrm{B}$ seems entitled to use necessary and proportionate force to defend himself - at least if B is not responsible for A's mistaken belief. If a reasonable, but mistaken, belief does not immunise one from liability to

\footnotetext{
41 The cancelling view is implausible in its own right, too. One cannot explain the necessity constraint on defensive harming without supposing that there is a reason of some kind to reduce harm to the attacker. ${ }^{42} \mathrm{~B}$ obtained a chance at life which is valuable. But this benefit is relatively minimal and would not be greater than the detriment caused by the duty to compensate. See [author's name removed].
} 
defensive harm, it is plausible that it should not immunise one from liability to compensatory harm. ${ }^{43}$

Another explanation is centred around responsibility. The basic idea is that persons ought to compensate for the damage caused by their responsible choices, and a choice is only 'responsible' in the relevant sense if it was a choice made in circumstances in which there was at least one reasonable alternative option. It could be said that $\mathrm{C}$ is not responsible in Dock 2 for the damage to $\mathrm{B}$ because $\mathrm{C}$ had no reasonable alternative but to act as $\mathrm{C}$ did: arguably, $\mathrm{C}$ would be in breach of a moral duty of easy rescue if $\mathrm{C}$ failed to save $\mathrm{A}$. But in what sense does $\mathrm{A}$ have a reasonable alternative to damaging the dock in Dock? The alternative to damaging the dock is death. If the absence of a reasonable alternative precludes a compensatory duty in Dock 2 , it should also do so in Dock. It may, however, be argued that $\mathrm{C}$ is morally required to damage the dock in Dock 2 , whereas $\mathrm{A}$ is not so required in Dock. Given that A acts without being morally required to act, it might be argued that A's choice makes A responsible for the damage. In Dock, the alternative of death is not morally impermissible. But if the basis of responsibility is choice within a reasonable set of options, it is not clear that a distinction can be sustained between alternatives that are morally impermissible and those that are extremely contrary to a person's prudential interest.

Here is my tentative view. In order to explain the absence of a compensatory duty in Self-defence, the continuity theorist probably needs to rely upon the idea that the reason not to harm the attacker does not take on its usual mandatory character, in virtue of the attacker's culpable imposition of a threat. The reason still obtains, and thus helps to explain why only necessary harm may be imposed upon the attacker. After the defensive harm has been imposed, the victim's non-mandatory reason not to be a causal source of harm to the attacker continues. But this nonmandatory reason may only require relatively minimal actions on the part of the victim. So, on this view, there is a weak reason to compensate, but it enters into the balance with all of the other demands on the victim's rational agency. It might be thought implausible that the victims of highly culpable, wrongful attacks have any reason at all to compensate their attackers. But if we accept that victims are required only to use necessary force to repel an attack, this implicitly accepts that there is still a reason, of some weight, not to harm the attacker. If that reason favoured using a less harmful means to repel the attack ex ante, it's not implausible to think it (weakly) favours lessening the harmful effect of the defensive harm ex post by compensation. ${ }^{44}$

43 For an exploration of the close relationship between defensive and compensatory liability, see G Sela, 'Torts as self-defence' (available on SSRN). See also [author's name removed], 'Defence and Compensation' (ms).

44 Victor Tadros made this or very similar point to me in discussion. 
This still leaves the question of how to explain Dock 2. I'm not entirely sure. Here are two possibilities. One view is that it would simply be inconsistent for morality to require compensation in cases in which morality requires the damage to be imposed. In Dock 2, C is arguably under a duty to impose the damage, since it carries little cost for $\mathrm{C}$ and it is the only means of saving a life. ${ }^{45}$ But then it would be inconsistent for morality to require the harm to be imposed and to be compensated for. This inconsistency does not arise, it might be said, in Dock where A is not morally required to damage the dock to save himself: only A's interests are at stake and so A is morally free to save his life or not. This view is problematic, however. First, there do seem to be situations in which morality requires compensation for damage that a person is under a moral duty to inflict. Suppose that due to your negligent supervision, your child is on the verge of ingesting your friend's very poisonous, but very valuable, tropical fish, which you have agreed to look after. The only way to protect your child is for you forcibly to grab the fish, thereby killing it. If the only way to protect your child from serious harm is to kill the fish, then you are morally required to do it. But presumably you also have a duty, now, to compensate your friend for the loss of his fish. Second, if acting on a moral requirement immunised one from a duty to compensate, then an odd distinction would arise between cases of supererogatory action and required action. Imagine a further variation on Dock $2-$ Dock 3 - in which, if C damages B's dock, $\mathrm{C}$ knows that this will crush one of C's legs. $\mathrm{C}$ is then probably not under a duty to crush his leg to save a stranger. If only required action immunises from a duty to compensate, then C's supererogatory action will mean that, by virtue of the operation of a continuity thesis, $\mathrm{C}$ has at least a reason to compensate. Third, this way of avoiding the problem of over-proliferation of compensatory duties for the continuity theses seems objectionably ad hoc. It amounts to saying that the thesis has application unless the damage-causer has acted pursuant to a moral requirement or, to deal with the last-mentioned problem, in a morally supererogatory manner.

The second way of dealing with Dock 2, which is more appealing, is to accept that $\mathrm{C}$ has a relatively weak, non-mandatory reason to compensate, in much the same way as the person who damages in justified self-defence. In support of this view, imagine that, having damaged the dock to save A, $\mathrm{C}$ can allocate a new dock to either $\mathrm{B}$ or some other person whose identical dock has been damaged by another justified harm-doer (these are troubled waters). Intuitively, I think, $\mathrm{C}$ has some reason to favour $\mathrm{B}$, in virtue of C's causal connection to B's damage.

45 For a defence of a linkage between the circumstances in which lesserevil justifications apply and duties of rescue, see H Frowe, 'Lesser-Evil Justifications for Harming: Why We're Required to Turn the Trolley' (2018) 68 Philosophical Quarterly 460. 
Legal Theory - Revised Submission

When compensation will not contribute to the alleviation of the damage

The continuity explanations I have developed so far can only justify a compensatory duty in Arm in rather limited circumstances. If the duty breached is a duty not be a cause of damage to a person's body by one's act, then future conformity to this duty will not require compensation where the victim or a third party has already undone the bodily damage. Suppose that the victim has paid for a replacement arm. If this is the case, then the payment of money by A will not contribute to the prevention of A's causing harm to B's bodily functioning: there is no risk of this occurring. And yet, intuitively, it seems odd that a wrongdoer can avoid being required to pay compensation simply by waiting on the victim to repair the injury himself. If the continuity explanations do not extend to such cases, then they have no ability to contribute to explaining many (most?) of the instances of compensation in law, where litigation occurs after the victim has been reimbursed by insurance or has obtained compensation by other means.

Can continuity theorists, then, justify a compensatory duty in A when B has already obtained preventative measures? They can if A has a duty not to cause B to be financially worse off as a result of A's wrongfully damaging B's body. If B pays for the arm, then B is financially worse off than B would be had A not wrongfully harmed B's body. By providing financial compensation to $\mathrm{B}, \mathrm{A}$ could then make it the case that $\mathrm{B}$ is not causally responsible for B's being financially worse off.

An objection to this elaboration of Duty continuity is that it posits a duty which does not exist. There is no duty, the objection runs, not to cause a person to be financially worse off as a result of a wrong, only a duty not to commit the wrong. For instance, it might be said that there is only a duty to keep one's promises not, additionally, a duty not to render a person worse off as a result of breaching one's promise. Alternatively, it might be considered question-begging to justify a duty to compensate for a loss caused by a wrong by appealing to a duty not to cause a person to suffer a loss as a result of a wrong; the duty not to cause a person to suffer a loss as a result of a wrong just is, one might object, a duty to compensate a person as a result of a wrong.

The idea that there are moral duties not to cause people to be financially worse off through wronging them is defensible, however. Such a duty could be considered to be a reflection of a general moral duty not to cause (by one's action) avoidable harm without justification. Depriving a person of financial resources can, sometimes, have a very significant impact on their ability to lead a flourishing life, especially in states with relatively modest welfare provision, or in situations in which insurance is prohibitively expensive. It can do this in various ways: by depriving of them the means to obtain or continue to have shelter, by reducing their ability to enjoy valuable relationships or by reducing their ability to participate in valuable activities. 
Clearly, not every time a person is caused to suffer financial loss do these effects occur. Indeed, a reduction in a person's finances may have no effect whatsoever on their well-being. This is true even once we take into account subtle harms that a reduction in one's resources may cause. Gardner argues that a reduction in one's ability to pursue one's existing goals can be a serious matter, simply because they are one's adopted goals (and possess a minimal level of value). 46 The reason is that life is finite. There is a limit to how much one can change course and move on. Consequently there can be a value in protecting you in what you have simply because you have it (and it is minimally valuable). But the idea (not one that Gardner espouses) that all of one's tangible property or intangible wealth is adopted into one's life goals seems implausible, at least for most people, or even that the possession of all of one's existing wealth is necessary for the maintenance of one's existing goals. Whether the law might be justified in adopting the presumption that reduction in wealth has a substantial impact on a person's goals is another question. So, at best, this argument holds out the hope of justifying compensatory duties in cases where deprivation of financial resources can justifiably be described as 'harm'.

An independent argument for a compensatory duty can be given in cases in which the harm has already been involuntarily repaired by the victim. In these cases, it seems unfair that the victim should have to bear the entirety of this cost. This unfairness could be explained, with the assistance of the continuity thesis, on the basis that the victim has involuntarily discharged the injurer's duty. By purchasing the arm, the victim removes the basis for the injurer's duty to pay compensation. Generally, it seems fair, as a starting point, that, as between two people, one of whom has a duty to repair damage by paying compensation, and another who has no duty to repair the damage, that the former be the one who bears the cost of compensation, even if both persons could cause the duty to repair no longer to exist. It is true that this not always the case. Suppose A decides, as a gift, to benefit B by paying off B's debts to C. C accepts A's payment in satisfaction of B's debt. Although A has borne a cost which B was under a duty to bear to C, it would not be unfair if B did not repay A. Under some circumstances, it might display a lack of gratitude, but there is no unfairness in not being repaid for a true gift, even when the gift has discharged another's duty. But in most, virtually all, cases in which a victim takes costly steps to repair their own damage, this is not intended to be a gift to the damage-causer. In many circumstances, it seems apt to describe the reparative actions of the victim in these cases as actions taken for want of a reasonable alternative. Absent the offer of immediate reparative action on the part of the damagecauser, it is frequently not reasonable to expect the victim to wait before making necessary expenditure to protect itself from the continuing damage, particularly when bodily rights are at stake. In these cases, then,

46 J Gardner, From Personal Life to Private Law, (Oxford University Press 2018), ch 5 . 
the victim bears the cost of discharging the injurer's duty in circumstances in which the victim had no reasonable alternative but to bear such a cost. Intuitively, this seems unfair. The continuity thesis still enters into the explanation of why it would be unfair for the injurer to avoid a duty to compensate here. This is because it explains the basis of the duty that the victim causes to be discharged: the injurer was under a continuing duty not unjustifiably to be a causal source of damage to the victim. This duty was discharged by the victim in circumstances in which the victim had no reasonable alternative but to do this. The continuity thesis, then, in combination with a principle of fairness, can justify duties to compensate even where the means to repair the injury have already been obtained.

\section{Beyond bodily rights}

Arm concerns relatively uncontroversial duties, and relatively uncontroversial reasons or rights. Most people will be willing to accept that there are reasons not to worsen people's bodily functioning (without their consent). But in many cases where a person intuitively has a duty to compensate, it is not obvious what reason has not been conformed to, and thus what reason remains to justify a compensatory duty. In this section, I will show that the continuity explanations extend to harm to property rights.

In a significant range of cases, the destruction of property is relatively unproblematic. To the extent that the property contributes significantly to one's well-being, it can justify the existence of relatively stringent duties upon others not to destroy it. The continuing reason in such cases could be one's reason not to significantly worsen a person's well-being. But in many cases, the continuing existence of a person's property makes no such contribution. For instance, it is difficult to believe that the moral justification of property rights of the extremely wealthy in non-essential goods that are not adopted into their life goals are justified by their well-being. ${ }^{47}$ The same is generally true of corporate property rights. Nonetheless, it is possible to justify duties of non-interference with these property rights, and duties to compensate, on at least two grounds. First, there is a collective interest in having valuable resources available for productive use, and thus free from certain kinds of damaging interference. In these cases, the duty to compensate can still, however, be justified by a continuity thesis, if there are continuing reasons, partly constitutive of duties, not to damage these resources in the collective interest. To the extent that payment of compensation will make available those valuable resources for exploitation, then the continuing reason could justify this payment. Second, duties to compensate can be justified in these cases on the grounds of general deterrence in order to maintain public order, under certain empirical assumptions. Suppose that there

${ }^{47}$ For a compelling defence of this claim, see R Cruft, 'Against Individualistic Justifications of Property Rights' (2006) 18 Utilitas 154, 165-167. 
would be many more harmful violations of property rights were people not legally empowered to trigger legal duties to pay compensation in respect of the violations of property rights in any kind of property. Perhaps the incentives created by individuals being so empowered are greater than those provided by morally permissible criminal law sanctions. If people have moral duties not to decrease the security enjoyed by others' valid moral property rights, they may have duties to bear compensatory burdens which incentivise others not to interfere with these rights.

(6) Objections

\section{(a) Different burdens}

This objection is that continuity thesis explanations of the duty to pay compensation fail to alleviate a concern that conformity to this duty can be very significantly more burdensome than conformity to the primary duty from which the secondary duty to compensate is said to arise. McBride and Bagshaw discuss a hypothetical (similar to a famous example given by Waldron ${ }^{48}$ ) in which a person's momentary, but negligent, lapse of concentration leads to momentous losses to an unfortunate motorcyclist. In such a case, the law might hold that person liable to pay millions of pounds. Continuity theorists, McBride and Bagshaw claim, move illegitimately from the thought that the imposition of, say, a primary duty to take reasonable care (which is relatively easy to comply with) is justified to the thought that a secondary duty to pay compensation for the breach of that duty is justified, when compliance with the latter duty might be much more burdensome than compliance with the former. ${ }^{49}$

This objection fails for two reasons. First, the fact that a duty is very burdensome is not a very strong reason for believing that it does not exist. As noted earlier, some negative duties can require a person to bear very significant costs. ${ }^{50}$ If I culpably throw a missile at you without justification, and the only way I can prevent the missile from killing you is to throw myself in front of the missile, I may be obligated to give up my own life in order to protect you. If the primary duty is justified by a very powerful reason, then it is not so surprising that the secondary duty of compensation exists, despite the costs of compliance being very high. Second, the pro tanto versions of the continuity thesis generate only pro tanto duties of compensation. This is compatible with those reasons being outweighed by more powerful countervailing reasons which emerge upon breach. Indeed, the continuity theses do not purport to describe all of the reasons that may bear upon a person's action after damaging a person, or to provide a complete account of how these reasons should be weighed

$48 \mathrm{~J}$ Waldron, 'Moments of Carelessness and Massive Loss' in D Owens (ed) Philosophical Foundations of Tort Law (OUP, 1995).

${ }_{49}$ NJ McBride and R Bagshaw, Tort Law, $5^{\text {th }}$ edn (Pearson Publishing) 803.

50 See above X. 
against each other. It may be that new circumstances emerge after a breach which justify the damage-causer failing to comply with their compensatory duty.

\section{(b) The role of wrongdoing}

Stephen Smith objects to the continuity thesis on the basis that it implies that conformity to a secondary duty to pay compensation is just as good as conformity to a primary duty not to damage. It has this implication, says Smith, in so far it holds that payment of compensation can undo the violation of a right or undo a wrong. ${ }^{51}$ In $\mathrm{Arm}$, the objection would run that removal of the arm and payment of compensation is just as good, morally speaking, as not removing the arm. Both amount to conformity to the duty not to be a cause of bodily damage by one's act without justification.

Here are two responses to this objection. First, it is often the case that by damaging a person one breaches multiple duties. For instance, unjustifiably and intentionally removing a person's arm involves damaging them, but it is also disrespectful: the act is wrongful not merely in virtue of damaging, but in virtue of treating the person as if they were at one's own use and disposal. ${ }^{52}$ It is difficult to see how this latter wrong can be 'undone' merely by payment of compensation. Such cases of disrespectful wronging are not limited to intentional wrongs, but likely extend to cases in which the wrongdoer's practical deliberation failed to accord sufficient weight to an interest of the person damaged; many cases of negligent damaging will fit this description. Second, it is often practically the case that some damage is irreparable such that perfect conformity to the duty not unjustifiably to be a causal source of damage is no longer possible. For example, it is generally the case that by damaging a person one sets back an autonomy interest of that person in being able to choose freely amongst certain options. If I am unable to use my leg for a period of time, my decisions about my life will be constrained during that period. Compensation will almost always be inadequate at addressing this kind of intangible harm, even if the leg is ultimately repaired.

51 S Smith, 'Duties, Liabilities, and Damages' (2011) 125 Harvard Law Review 17271753.

52 For discussion of the distinction between use-based and harm or damage-based wrongs, see A Ripstein, Private Wrongs (HUP, 2016). 
But Smith has a further objection. ${ }^{53}$ The continuity thesis embodies a 'model in which wrongs qua wrongs have no significance'. 54 The reason for this is that the fact of wrongdoing is not itself a normative reason for the existence of a compensatory duty under Duty and reasons continuity. Recall that it is the reasons which justified the existence of the duty which, according to Reasons continuity, continue to demand conformity. Clearly, the fact that the primary duty was breached is not a reason which justified the existence of the primary duty. So the breach of the duty is not one of the reasons which justifies the compensatory duty under Reasons continuity.

Smith offers this point as a descriptive objection to Reasons continuity as an account of the law's understanding of why compensatory legal duties arise. But should this objection be worrisome from a purely moral perspective? It might be considered counterintuitive that under Reasons continuity wrongdoing is not itself a justificatory reason for the existence of a compensatory moral duty. A response to this point, however, is that wrongdoing typically changes the non-normative circumstances such that we can usually say that the duty to compensate arises 'because of' the wrongdoing. Compare one's duty to take reasonable care. Suppose you are an employer and, by virtue of this duty, you need to set up a safe system of work, call it system A. But now suppose that, in virtue of new technologies, your workers could be made substantially safer at little cost. These new circumstances require system B. Under the continuity thesis, the duty to pay compensation arises in the same way as the duty to install system B - the breach of the duty is just a changed factual circumstance to which the original reasons for that duty now apply. One's rational failure is just a background fact, rather than itself a normative reason for the duty. But this is consistent with the idea that compensatory duties arise in a sense because of wrongdoing, to the extent that wrongdoing changes the non-normative facts.

It is also compatible with the continuity thesis that the fact of wrongdoing itself may give rise to reasons for certain other kinds of response to wrongdoing, which are constitutively bound up with one's being a wrongdoer. For instance, if one has reasons to feel remorse or to apologise, these reasons may arise directly in virtue of the fact that one has failed to conform to reason. The fact that one has failed to conform necessarily enters into the justification of such reasons.

However, it may be further objected that Reasons continuity cannot account for the stringency of moral compensatory duties arising out

${ }^{53}$ I should stress that Smith raises this objection in the context of a discussion of legal duties, but given his Razian understanding of legal duties as the law's understanding of our moral duties, I think his objections here can be transferred to the purely moral duties. See also V Tadros, 'Secondary duties' in P Miller and J Oberdiek (eds) Civil Wrongs and Justice in Private Law (OUP, 2020) for related objections which, like Smith, claim an intrinsic significance for wrongdoing.

54 Smith (n 20) 1753. 
wrongdoing. ${ }^{55}$ Suppose that A has wrongfully damaged B's body in a car accident and A can either take steps which will prevent harm of size $n$ arising from this event to B, or effect an easy rescue of another person, C, averting harm of size $n$ to $\mathrm{C}$, where $\mathrm{A}$ has a moral duty of easy rescue to $\mathrm{C}$. Intuitively, A has a duty to take steps to prevent harm to the person A has wronged: B. Other things being equal, this suggests, one has a more stringent duty to compensate for wrongful harm than to fulfil a duty to protect from harm. In both cases, however, the reasons for the duty are the same: a person's interest in not suffering bodily injury justifies the duty in both cases. If the reasons justifying the duty are the same in both cases, then why are the duties not of equal stringency?

This objection can be met in three ways. First, one might simply observe that Reasons continuity is an account of when and why a compensatory duty arises, not its stringency. This would reduce the theoretical ambition of Reasons continuity. Second, similarly, one might say that Reasons continuity provides a defeasibly sufficient condition of the existence of a compensatory duty, while there may be others, such as wrongdoing. Third, and most persuasively, it can be argued that the reasons for the primary duties are importantly different in the example above. They are different in a way which explains the differing stringency of the compensatory duty. In the car accident, one's compensatory duty is justified by the reasons not to harm that persist post breach, not merely reasons of well-being in general. If one does nothing in relation to the potential harm caused by the negligent car accident, then one will be harming, not merely not aiding.

\section{(c) Liability, not duty}

Gardner takes as the moral explanandum duties to compensate. ${ }^{56}$ The continuity thesis is the explanans. One might wonder, however, whether this accurately reflects the moral landscape. The argument has been made that the law only recognises a liability to pay compensation upon breach, not a duty. ${ }^{57}$ Should we think that this is true in morality, apart from the law? Call the view that the secondary normative relation upon breach is immediately a duty to compensate, the 'duty view'. Call the view that the normative relation is immediately only a liability, the 'liability view'.

The starting point in thinking about this is that it would be odd if the primary right-duty relation transformed into a power-liability relation. If the original reasons stacked up so that I had a duty not to injure you, and those reasons can still be conformed to up to a point, why does the original duty transform into a liability? What has changed in the post-breach world is that some of the original reasons for the duty, and, perhaps, the reason given by the duty itself, cannot be conformed to, but it is not clear why the fact that the governing reasons are less-conformable-to in the

55 I am grateful to Hasan Dindjer here.

56 Gardner, (n 33) 33.

57 See below, X. 
post-breach world should change the normative relation between the parties.

The duty view also explains why wrongdoers have certain other duties upon wrongfully causing loss. If you bash your car into my car in a car park, smashing the taillight, when talking on your phone, surely you have a duty not to drive off without doing anything. At a minimum, you have a duty to leave your contact details on my car and explain what happened. This duty is naturally explained by the fact that you have a duty to compensate me. This duty explains why you must take steps towards its fulfilment. 58

The duty view also explains straightforwardly why it is that a person who breaches a duty and thereby incapacitates their victim surely has a duty to contribute towards measures which reduce that incapacity. For instance, you culpably render me unconscious by knocking me over in your car. You now have a duty to protect me from dangers risked by this act (for instance, by calling an ambulance or moving me to the side of the street). Since a liability is correlative to a normative power, and since a power must be exercised by an intentional act, it cannot be that this duty is sourced in such a power, since, incapacitated, I could not exercise any such power. The liability view would need to treat this as an exceptional case when a compensatory duty arises independently of the exercise of the power. ${ }^{59}$

However, there are two reasons that might be offered as to why the normative relation changes to a power-liability relation. The first is that wrongdoing affects the communicative message of compensation. Suppose you brutally snap my arm and then immediately transfer the cost of a prosthetic arm to my bank account. Doing so will repair harm but also probably lead to further harm, or at least distress. It will lead to the latter in so far as your immediately transferring money to me suggests that you think it is permissible to harm me so long as you pay me afterwards. By substituting a duty to compensate for a liability, morality puts control in the victim's hands, so to speak, and thereby obviates the possibility of this message. This is unconvincing, however. Whether immediately paying compensation has the alleged message depends on a variety of contextual factors; sometimes immediately paying compensation could communicate that one deeply regrets the wrongful harm. Furthermore, even if an immediate duty of compensation did increase the probability of this kind of communicative harm, morality may still require it. Part of the moral difficulty of being a wrongful injurer may be that one has a duty that needs to be performed sensitively in order to avoid adding insult to injury.

${ }^{58}$ For the suggestion that liabilities can give rise to duties in and of themselves, see NJ McBride, 'Stephen A Smith on Duties and Liabilities': available here

https://papers.ssrn.com/sol3/papers.cfm?abstract id=2668742.

59 In English law, where A puts it out of B's power to communicate the exercise of a legal power to A, the requirement of communication to $\mathrm{A}$ is dropped: Universal Carriers Corp v Citati [1957] 2 QB 402. 
A second reason is that it may often be very unclear what 'next-best' conformity to an original reason for a duty requires. Perhaps the victim will suffer loss in the future, the extent of which is difficult to determine, and only determinable with the co-operation of the victim, and perhaps the steps needed to make it the case that harm does not eventuate are dependent significantly upon the victim's desires (what kind of new arm do you want?). ${ }^{60}$ This epistemic uncertainty might make it unfair that the wrongdoer has an immediate duty to compensate, rather than a liability to compensate, which crystallises into a duty when the victim declares what compensation is owed. Again, however, the fact that a duty is difficult to comply with seems insufficient reason for doubting that it exists. The best view may be that where next-best conformity is genuinely undetermined, and depends upon the victim's identifying what next-best conformity will amount to, that only a liability exists, not a duty, but generally there is indeed a duty to compensate immediately upon breach.

Regardless of whether we believe that a duty or only a liability exists at the time of breach, the continuity thesis is still true and interesting if it helps to justify either normative relation. If the victim's normative power, if that is what exists, is a power to impose a duty of next-best conformity, then it seems clear that the continuity thesis helps to explain the existence of the liability. In this way, the truth of Reasons continuity is independent of the truth of the duty or liability view.

\section{Conclusion}

In this paper, I have aimed to clarify and defend continuity thesis explanations of duties to compensate. I argued that the most plausible versions of duty, right, and reason continuity appeal to general duties and reasons not to be a causal source of damage, unjustifiably, to another person. These general duties and reasons justify more specific duties and reasons prior to and after damage has been inflicted. Further, I have identified, and aimed to address, a set of largely undiscussed problems continuity views face, notably the problem of over-proliferation of duties to compensate in cases of justified damage, and the problem of the damage already having been repaired.

60 Smith above (n 20). 